\title{
On the Road to an International Platform for Exchanging Research for Information and Technology in Education and Learning
}

\author{
Toshio Mochizuki* and Ryo Takaoka**
}

\section{Introduction of the Joint Journal}

Information and Technology in Education and Learning (ITEL) was recently launched as a joint international journal published by the Japan Society for Educational Technology (JSET) and the Japanese Society for Information and Systems in Education (JSiSE). As the successor of Educational Technology Research published by JSET and The Journal of Information and Systems in Education published by JSiSE, ITEL aims to be an international platform for communicating research in educational technology and information systems in education.

One of the important goals of ITEL is to enhance researchers' and students' ability to disseminate achievements in educational technology and information systems in education in Japan. As many educational researchers around the globe know, educational practices and research in Japan for improving students' learning processes, such as "lesson study," have been carried out for decades at an excellent level from an international perspective ${ }^{[1]}$. Researchers in information systems or technology have also investigated systemic improvements in educational environments using innovative technologies in a timely manner. However, most of our research achievements were published only in Japanese journals, therefore such publications could not be disseminated to people around the world. This means that Japan is in danger of becoming isolated from international academic or educational practices, where many insightful scholars exchange and build their research to explore and advance educational environments. Taking into consideration the complex and unique background and context of culture and practices in education and learning in Japan, this journal was launched to serve as a booster for scholars and students associated with the

\footnotetext{
* School of Network and Information, Senshu University, Japan

** Graduate School of Education, Yamaguchi University, Japan
}

above-mentioned societies to collaborate and disseminate promising research successfully.

Another important goal of ITEL is to create a forum for international exchange of research on information and technology in education and learning. Concretely speaking, we have welcomed students and researchers from various countries in the Asia-Pacific region and beyond to our universities and institutions. We have often hosted international conferences on information and technology in education and learning in Japan. We believe that such opportunities for research exchange produce material that fosters international research connections with various countries. There are also ongoing exchanges with researchers who advance the latest knowledge through their study abroad. With the help of such researchers, we would like to introduce a variety of leading research and practices conducted around the world. In this way, we hope to create new communities of educational practices and research with international cooperation in the area of information and technology in education and learning.

Teaching and learning are closely related to the information and technologies that support various forms of communication. In the area of information and technology in education and learning, not only educational technology and information systems in education, but also educational psychology, cognitive science, the learning sciences, data and information science, and various other fields of humanities and social sciences, as well as information technology, strive for the advancement of research every day. We expect that ITEL will be a bridge not only to reach Asia, but also to span the globe, by bringing together a wide range of research on information and technology in education and learning from various disciplines. The name of the journal, ITEL, reflects our hope for it to be a place where insightful research on information and technology in education and learning from various countries and domains can be put together and where researchers can communicate with each other. 


\section{Introducing the Inaugural Volume}

To achieve the aims described in the previous sections, the ITEL Editorial Board has set six categories of original papers: invited papers, regular papers, practice papers, development papers, review papers, and short papers. We also have a different paper category called "Translation" which is a complete English translation of papers originally written in Japanese and already published in Japan Journal of Educational Technology which is one of our flagship Japanese journals.

The inaugural volume of ITEL comprises four precious invited papers, five great regular papers, three informative practice papers, one interesting development paper, one thorough review paper in the area of Content and Language Integrated Learning (CLIL), and two promising short papers. This volume also has eight translation papers that were reviewed and transferred by the Editorial Board of Japan Journal of Educational Technology. This editorial aims to introduce the articles briefly in order for the readers to endeavor and find interesting research topics in the area of information and technology in education and learning.

\subsection{Invited Papers}

Invited papers introduce the latest research trends in accordance with the theme of each volume and are written by promising scholars selected by the ITEL Editorial Board. The theme of the inaugural volume is "On the road to an international forum of information and technology in education and learning." Four invited researchers or research teams introduced the current status of a particular field in this inaugral volume.

We first invited two papers that introduce the history and academic activities of the two above-mentioned academic societies sponsoring this joint journal, the papers written by the presidents of each society, in order to dessiminate our current position and future directions. These two papers inform readers about the background of the sponsoring societies and context of the joint launch of ITEL.

Katsuaki Suzuki ${ }^{[2]}$, the eighth president of JSET, described the JSET's contribution toward the supersumart society (Society 5.0, proposed by the Japanese government). In the 37 years of JSET's history, the society has been active under the broad research interests of its members and has formed an internationally distinc- tive interdisciplinary field that integrates humanities, social sciences, sciences, and engineering, in addition to other human-related disciplines. This article introduces various specific fields that have formed the area of educational technology over the past decades, as well as the achievements that have contributed to the practical advancement of informatization in schools and other educational fields.

Akihiko Kashihara ${ }^{[3]}$, the current JSiSE president, introduced the JSiSE and its research activities mainly based on informatics, information science, and technology. JSiSE mainly focuses on the technological aspects of the learner or teacher support, as well as modeling or theorizing learning from an informatics perspective. This article describes how the research of information and technology in education and learning in JSiSE has progressed over nearly a half century, and how it has introduced a variety of timely and advanced technologies into education and learning and how it has interacted with or impacted a variety of learning theories further advancing research in education and learning.

The other two invited papers were selected based on the theme of the inaugural volume and the current research trends of information and technology in education and learning.

Learning analytics is a major research trend and is a promising topic in information and technology in education and learning. Oshima and Shaffer ${ }^{[4]}$ introduced their promising learning analytics methods and backgrounds of their research, or "the new perspective of learning," and discussed how these analytic technologies support researchers in analyzing learners' discourse in collaborative learning. Their learning analytics methods, generally classified as socio-semantic network analysis (SSNA), are considered promising techniques for analyzing how collaboration among students builds on and generates new ideas and knowledge. These techniques also help researchers and teachers identify pivotal points that contribute to the advancement of learning or how the transformation of individuals' epistemic networks (i.e., a set of relationships that connects skills, knowledge, and values that a learner uses to make decisions and take action in the world ${ }^{[5]}$ ) occurs during the collaborative discourse of learning. These two methods are increasingly being used in the communities of learning analytics and the learning sciences, especially to reveal learning in practice with information and technology.

Teaching and learning how to understand or inter- 
pret a variety of conflicting information in the post-truth era is another big challenge in the current situation in relation to information and technology in education and learning. People encounter rampant conflicting information from unreliable and reliable sources in daily problem solving on regular basis. Even reliable sources sometimes introduce information with low-quality evidence. Thus, many researchers in media literacy, information problem solving, and epistemic cognition have taken up this research topic. However, how can an innovative inquiry curriculum that is being currently developed and implemented help students enhance their epistemic growth? Chinn, Duncan, and Av-Shalom ${ }^{[6]}$ addressed this question in their article by evaluating their inquiry-based science curriculum named PRACCIS (Promoting Reasoning and Conceptual Change in Science) from the viewpoint of their evidence evaluation framework, called "Grasp of Evidence (GoE) Framework." After introducing the GoE Framework briefly, they discussed expanding this framework to the analytic framework in order to guide designs of learning environments for epistemic education-education to develop students' competencies to demonstrate success in knowing, such as forming accurate judgments or evaluating arguments, across a range of situations, as well as appraising accurately through meta-competence when success can be achieved reliably enough ${ }^{[7]}$. The article also demonstrates how to evaluate designed learning environments and curricula in accordance with the GoE Framework, using several examples of the PRACCIS Curriculum and educational materials in a thorough manner.

These two papers represent the forefront of technological/analytical or educational aspects of the current research trends and show several directions toward research and practices anticipated in the near future in the field of information and technology in education and learning.

\subsection{Regular Papers}

Regular papers are one of the categories of research papers that describe original rigorous studies related to information and technology in education and learning. This paper category covers a variety of topics related to education and learning, with diverse research methodologies, such as quantitative, qualitative, or mixed methods, in a varied setting of formal and informal education and learning in a variety of areas.
The first regular paper written by Katsumi and Tamura $^{[8]}$ presents an interesting study based on an international survey across three Asia-Pacific countries that reports on parents' perceptions regarding their children's use of information and communication technology (ICT). Their international comparative study shows an interesting common phenomenon that parents in these countries have significant concerns regarding their children's use of the internet, regardless of differences in regulations or curricula for children's preparation for the use of ICT. This means that the early educational curriculum should address this issue in a number of countries.

Muroya, Seta, and Hayashi ${ }^{[9]}$ conducted an interesting study based on the Japanese specific cultural aspect, cartoons. Comics and animations were originally not popular outside Japan, but their popularity is growing daily and thus becoming a global phenomenon. Cartoon comics regarding Japanese and world history are well known, even in schools, and are one of the popular means for studying history for school children in Japan. The authors looked at this interesting aspect as the key to their research and developed an interesting system for learners to engage in historical reasoning in inquiry-based learning.

Another interesting regular paper on the intersection between cultural practices and educational system development was described by Ashida, Tokumaru, and Kojiri ${ }^{[10]}$. Although most contributions to the inaugral volume target the formal education setting, this article is one of the few papers that focus on the informal learning setting. The authors focused in this paper on novel writing by beginner writers and designed a support system that guides the writers to follow characters' emotions in accordance with the story arcs which is possible readers' emotional trajectories through the story in order to maximize the readers' sympathy. The system also provides feedback to the writers if there were gaps between the characters' emotional trajectories and the guide on the system.

These three regular papers reflect the Japanese cultural aspects of the research on information and technology in education and learning, while the other two regular papers address current important issues in Japan and around the world in order to promote research and practice in information and technology in education and learning.

One important issue is enhancing students' computational thinking at every school level, which is 
included in the current educational reforms in Japan under the policy vision of Society $5.0^{[2]}$. Fukui, Sasaki, Hagikura, Hayashi, and Hirashima's article ${ }^{[11]}$ deals with this issue especially focusing on improvement of students' logical thinking skills such as a 'else-if-then' statement workflow, which is one of the areas that laystudents need to work hard on for understanding how a computer algorithm works. This article proposes a method that applies a yes/no chart to train this type of computational thinking skill by the development of a learning system. In this article, an experimental study with students from high schools and universities also presents the effectiveness of the proposed method for learning such computational thinking as equivalent to visual programming which is another well-known strategy of learning computational thinking that helps students understand the logical workflow.

Another important issue is enhancing students' motivation and regulation in online learning in the context of COVID-19. The COVID-19 pandemic has tremendously impacted educational practices and research worldwide. Online teaching and learning have been disseminated regardless of school level, even in Japan. However, most instructors have struggled with students' motivation and engagement in online courses or school activities in recent years because of the nature of online learning, such as the lack of communication channels or the flexible nature of teaching and learning. Okada ${ }^{[12]}$ dealt with this issue and pointed out the importance of teachers' autonomy support, that is, the instructional effort to organize appropriate learning environments and to establish a good teacher-student relationship in order to support students' need for autonomy. This article describes a psychological study in an online class in which the study investigated a hypothetical model of the teachers' autonomy support that affects students' intrinsic motivation, metacognition, and self-evaluated achievements. The study revealed that teachers' teaching styles, such as autonomy-supportive teaching, are key factors to maintaining students' motivation and achievements wherein the latter two are also related to metacognition in online learning. These results seem to be consistent with the lines of research on online moderating $^{[13]}$ and mentoring ${ }^{[14]}$.

\subsection{Practice Papers}

Practice papers describe studies on educational practices or studies in practical situations in education (formal or informal) and learning and present their results with regard to information and technology and how the educational practices and learning proceed in the study. The three informative practice papers in this volume represent interesting studies on educational practices that investigated a type of learning strategy in diverse settings, either online or in-person, using ICT.

The article by Yagi, M. Suzuki, Tsuzuku, Murakami, Nakano, and K. Suzuki ${ }^{[15]}$ deals with a similar research topic to Okada's article ${ }^{[14]}$ - self-regulation in online learning. In the study by Yagi et al., the authors proposed implementing an orientation course that covered some topics to foster self-regulated learning skills as well as how to use technologies for the online learning platform. Their design-based research over two years in a nursing education program focused on the importance of planning activities that enhanced students' awareness of learning processes and reflection, revealing that introducing planning and reflection activities, even in the introductory course for the technology infrastructure, significantly improved learners' monitoring and reflection on their learning processes in online learning.

In contrast, Ikejiri, Yamamoto, Nakano, Yoneda, and Yamauchi ${ }^{[16]}$ studied in-person project-based learning, describing an interesting educational program design with Google Workspace (formerly called "G Suite") in a high school setting. The topic of project-based learning was the anticipated big earthquake around Osaka, Japan, which is expected to be almost similar to or larger than the Great Tohoku Earthquake in 2011. The project was designed to encourage students to think about how to deal with disasters so the students could arrive at two conflicting positions: the first supports the idea that volunteers should help victims in the disaster area in-person, while the other supports the idea that volunteers should help the disaster area remotely. The students who participated in the project-based learning program worked with Google Workspace with guidance from the instructor by organizing positive and negative aspects of either position, then developed their arguments about the position they supported and finally generated their solution. The article describes the instructional flow and students' learning process in the classroom practice and shows that the teacher's feedback was effective in the student-centered learning processes which was made possible by using Google Workspace that allowed the teacher to synchronously 
monitor the students' progress.

Mochizuki and Tsubakimoto ${ }^{[17]}$ described another type of in-person collaborative learning activity using an application called eJournalPlus, which was designed to support students in reading an electronic text and developing their ideas based on what the text describes. Interestingly, the application supported exchanging two types of products of the students' learning activity. The first type of the products was the graphical representations that illustrated how each student understood the text and generated their ideas based on the text. The second type of the products was the essay that each student generated based on the graphical representations. The article describes a quasi-experimental study in a university class which revealed that their unique interface, which allowed users to exchange ideas or opinions both in the graphical representations or the essays, improved their critical thinking process while exchanging their ideas and revising their essays.

\subsection{Development Paper}

Development papers focus on the development of technology-based solutions such as software or new hardware using diverse ICTs, which aim to improve education and learning in a variety of areas. This volume contains only one development paper that represents an interesting idea of using a well-known type of display found in metropolitan areas worldwide, called "interactive digital signage" (IDS), with the background of the Japanese environmental context.

As the preparation for possible disasters (not only earthquakes but also heavy rain, floods, fires, or tornadoes) is usually emphasized in either formal or informal education in Japan, Mitsuhara and Shishibor ${ }^{[18]}$ described their system development for informal learning for disaster readiness using IDS. The system includes an interactive quiz application in which users are required to show embodied expressions to answer questions regarding disaster readiness in daily settings. Most disasters occur when least expected; thus, learners can easily engage in learning activities for disaster readiness as they encounter IDS when walking around major train stations or city areas. As shown in the experiment described in the paper, the learning experience with their proposed system was effective in attracting children when the system applied embodied interactions. We consider that the results indicate that this type of innovative system development can enhance learners' attention or curiosity in disaster readiness in their daily lives.

\subsection{Short Papers}

Short papers are manuscripts that include new approaches in education and learning or pioneering studies in educational technology or educational practice using ICTs in formal or informal education and learning. The inaugural volume of ITEL includes two short papers that describe promising ideas in small studies.

Akamatsu and Goto ${ }^{[19]}$ dealt with an emerging issue in the area of information and technology in education and learning: resilience to failure as a non-cognitive skill conceptualized by the OECD. In their study, the researchers conducted a survey of junior high school students in Japan to identify several types of students in their failure beliefs and to analyze the characteristics of each type of student with regard to their academic and social outcomes. According to the results, the researchers discussed the necessity of teachers' awareness of the social aspects of students' competence, such as help seeking and friendship, which students who have high level of fear should acquire.

Kotani and Yoshimi ${ }^{[20]}$ addressed a different important research topic regarding evaluating English proficiency based on students' performance in a classroom setting. Estimating students' English proficiency in practice has been considered a significant challenge in recent years in Japan. In this article, the researchers proposed a method for evaluating students' English proficiency based on read-aloud performance, read-aloud accuracy, speech rate in words per minute, and ease of reading aloud. They collected data with Japanese undergraduate students in order to examine what combination of the performance indices estimated well the students' English proficiency and revealed that using all three indices for the estimation outperformed all other combinations.

The studies described in these papers are still in their nascent period of research; however, they seem to be promising for producing practically useful achievements in future studies.

\subsection{Review Paper}

Review papers are expected to summarize recent and 
past research history and provide directions for research on information and technology in education and learning. This inaugural volume encompasses only one review paper; however, the review paper described by Hao and Yamada ${ }^{[21]}$ reviews the research on CLIL and discusses their perspectives on the possible directions of CLIL research.

CLIL has recently attracted educators who are interested in language learning in an authentic setting; CLIL seems to be promising, as students can enhance their engagement in learning both language and content subjects in parallel. In this article, 100 peer-reviewed articles were systematically selected and reviewed to address several research questions regarding the distribution of studies related to CLIL over the past 10 years, related to target language, related to involvement of the First Principles of Instruction (FPI) ${ }^{[22]}$, and related to use of ICT. The article describes that the current state of CLIL research mostly focuses on English as a foreign language, instead of other language learning. The researchers also pointed out that the use of ICT in CLIL is promising, especially in distance learning setting; however, this is still a new area of study. The lack of attention to FPI in addition to the use of technology has also been pointed out in this article. This article discusses promising ideas to extend the framework of CLIL from the viewpoint of instructional design and the use of ICT.

\subsection{Translations}

Translations are exact English translations from papers that have been published in Japan Journal of Educational Technology (Japanese version), which is JSET's signature journal. The aim of this category is to disseminate research achievements produced in Japan, even if originally written in Japanese, to the world. In fact, some educational research conducted in Japanese schools with significant levels of specific cultural contexts has difficulty in situating the study in a global context, thus, researchers are forced to first publish their achievements in Japanese.

This inaugural volume encompasses eight translation papers that reflect the diversity of research in the area of educational technology in Japan such as information system development for school education in Japan, a survey of computing education at Japanese schools, psychological research in language educa- tion or science education, and research on educational practices for improving specific school educational programs. The society's research activities also cover an informal learning setting; one of the translation papers is an interesting study on job interviews and personality. Other types of research on education and learning, such as corporate training, teacher training, and education using games, will be introduced in the next volumes.

\section{Next Steps on the Road}

All articles published in ITEL are subject to a rigorous and prudent peer review process, typically going through one round of revision under the direction of one editorial board member along with one associate editor and one consulting editor from the Editorial Board, to identify the most important contributions in an appropriate way. Even if one round of revision is not sufficient for publication, the editorial board usually encourages the authors to re-attempt submission after revising their manuscripts to meet our rigorous standards and ensure that only quality papers are published. Once a paper is officially accepted, it is typeset, assigned a unique digital object identifier (DOI) and posted on J-STAGE, the Japanese platform for open access publications, where it is available for free permanently.

The ITEL Editorial Board is very conscious about the circulation of published articles worldwide. We believe that introducing the international citation system, the IEEE Reference Style, will enhance and visualize the citation network among research achievements on ITEL and other articles published in diverse journals. We will make this journal explicitly open. Articles published from the next volume will be licensed CC-BYNC-ND under the Creative Commons License 4.0 to enable distribution of the published articles on ITEL. We will also apply to the Directory of Open Access Journals (DOAJ) to accredit ITEL as a qualified journal and make ITEL visible to the academic communities.

Finally, the entire editorial board of this inaugural volume would like to express their deepest gratitude to all the contributors, editorial board members, reviewers, and readers, both society members and non-members. We believe that all 29 contributions (except for Translations) to this inaugural volume were extremely valuable for the quality of this launching journal, while some of those were unfortunately pended for publication. In addition, we are grateful to Drs. Yuhei 
Yamauchi (The University of Tokyo, JSET) and Tsukasa Hirashima (Hiroshima University, JSiSE) for initiating this joint project of the two academic societies in such fruitful way.

The next steps of ITEL will depend on your future contributions. We hope to receive many more manuscripts from various fields that are related to information and technology in education and learning for our second and subsequent volumes. The theme of the next volume will be "Toward international collaborations: Lessons and practices." We look forward to receiving your submissions in the near future.

Editorial Board Members for the Inaugural Volume:

Toshio Mochizuki (Senshu University, JSET, Outgoing Co-Editor-in-Chief)

Junko Nemoto (Meiji Gakuin University, JSET, Associate Editor)

Tatsushi Fukaya (Hiroshima University, JSET)

Takeshi Matsuda (Tokyo Metropolitan University, JSET)

Yusuke Morita (Waseda University, JSET)

Hiroaki Ogata (Kyoto University, JSET, Incoming Co-Editor-in-Chief)

Hiroki Oura (Tokyo University of Science, JSET)

Shinichi Sato (Nihon Fukushi University, JSET)

Masanori Yamada (Kyushu University, JSET)

Yuhei Yamauchi (The University of Tokyo, JSET)

Ryo Takaoka (Yamaguchi University, JSiSE, Co-Editorin-Chief).

Hidenobu Kunichika (Kyushu Institute of Technology, JSiSE, Associate Editor)

Yoshiko Goda (Kumamoto University, JSiSE)

Yuki Hayashi (Osaka Prefecture University, JSiSE)

Yuki Hirai (Shinshu University, JSiSE)

Rieko Inaba (Tsuda University, JSiSE)

Yurie Iribe (Aichi Prefectural University, JSiSE)

Tomoko Kashima (Kindai University, JSiSE)

Satoru Kogure (Shizuoka University, JSiSE)

Kazuaki Kojima (Teikyo University, JSiSE)

Yukihiro Matsubara (Hiroshima City University, JSiSE)

Kenji Matsuura (Tokushima University, JSiSE)

Yoshimitsu Miyazawa (The National Center for University Entrance Examinations, JSiSE)

Koichi Ota (Japan Advanced Institute of Science and Technology, JSiSE)

Hitomi Saito (Aichi University of Education, JSiSE)

Yasuhiko Tsuji (The Open University of Japan, JSiSE)
Takahito Tomoto (Tokyo Polytechnic University, JSiSE)

\section{List of Reviewers:}

Taisuke Akimoto (Kyushu Institute of Technology, Japan)

Hironori Egi (The University of Electro-Communications, Japan)

Hideo Funaoi (Soka University, Japan)

Wakako Fushikida (Tokyo Metropolitan University, JSET)

Junko Handa (Polytechnic University, Japan)

Takamitsu Hashimoto (The National Center for University Entrance Examinations)

Hisashi Hatakeyama (Hosei University, Japan)

Yusuke Hayashi (Hiroshima University, Japan)

Hisashi Ichikawa (Iwate Prefectural University, Japan)

Tomoo Inoue (Tsukuba University, Japan)

Naoko Ishikawa (Waseda University, Japan)

Masaharu Kage (Keio University, Japan)

Mizue Kayama (Shinshu University, Japan)

Toshihiro Kita (Kumamoto University, Japan)

Akiko Kobayashi (Shimane Prefectural University, Japan)

Yusuke Kometani (Kagawa University, Japan)

Hisayoshi Kunimune (Chiba Institute of Technology, Japan)

Hideya Matsukawa (Tohoku University, Japan)

Kahoko Matsumoto (Tokai University, Japan)

Motoki Miura (Chiba Institute of Technology, Japan)

Yoshimitsu Miyazawa (The National Center for University Entrance Examinations, Japan)

Masayuki Murakami (Osaka University, Japan)

Shoichi Nakamura (Fukushima University, Japan)

Toshihisa Nishimori (Osaka University, Japan)

Takuma Nishimura (Kochi University of Technology, Japan)

Hironari Nozaki (Aichi University of Education, Japan)

Ayano Ohsaki (Advanced Institute of Industrial Technology, Japan)

Ryo Okada (Kagawa University, Japan)

Yasuhisa Okazaki (Saga University, Japan)

Yuichi Ono (Tsukuba University, Japan)

Shien Sakai (Chiba University of Commerce, Japan)

Tomomi Sato (Aichi Shukutoku University, Japan)

Kojiro Shojima (The National Center for University Entrance Examinations, Japan)

Masayuki Suzuki (Yokohama National University, Japan) 
Fuminori Takahashi (Shokei University Junior College, Japan)

Masanori Takagi (Iwate Prefectural University, Japan)

Koji Tanaka (Kanazawa Institute of Technology, Japan)

Yuta Taniguchi (Kyushu University, Japan)

Eiji Tomida (Ehime University, Japan)

Masaki Uto (The University of Electro-Communications, Japan)

Atsushi Yoshikawa (Tokyo Institute of Technology, Japan)

\section{References}

[1] J. W. Stigler and J. Hiebert, The Teaching Gap: Best Ideas from the World's Teachers for Improving Education in the Classroom. New York, USA: The Free Press, 1999.

[2] K. Suzuki, "Contribution of the Japan Society for Educational Technology toward a Super-Smart Society (Society 5.0)," Inf. Technol. Educ. Learn., vol. 1, p001, 2021.

[3] A. Kashihara, "Research on informatics for learning and education," Inf. Technol. Educ. Learn., vol. 1, p002, 2021.

[4] J. Oshima and D. W. Shaffer, "Learning analytics for a new epistemological perspective of learning," Inf. Technol. Educ. Learn., vol. 1, Inv.p003, 2021.

[5] A. Csanadi, B. Eagan, J. Kollar, D. W. Shaffer, and F. Fischer, "When coding-and-counting is not enough: Using epistemic network analysis (ENA) to analyze verbal data in CSCL research," Int. J. Computer-Supported Collab. Learn., vol. 13, no. 4, pp. 419-438, 2018.

[6] C. A. Chinn, R. G. Duncan, and N. Av-Shalom, "Applying the Grasp-of-Evidence framework to design and evaluate epistemically complex learning environments," Inf. Technol. Educ. Learn., vol. 1, Inv.p004, 2021.

[7] S. Barzilai and C. A. Chinn, "On the goals of epistemic education: Promoting apt epistemic performance," $J$. Learn. Sci., vol. 27, no. 3, pp. 353-389, 2018.

[8] K. Katsumi and T. Tamura, "International comparison of parental perception regarding young children's ICT usage," Inf. Technol. Educ. Learn., vol. 1, Reg.p001, 2021.

[9] D. Muroya, K. Seta, and Y. Hayashi, "Semantically enhanced historical cartoons promoting historical interpretation," Inf. Technol. Educ. Learn., vol. 1, Reg.p002, 2021.

[10] A. Ashida, M. Tokumaru, and T. Kojiri, "Characters' emotion design support system for creating novels based on story arcs of target readers," Inf. Technol. Educ. Learn., vol. 1, Reg.p005, 2021.
[11] M. Fukui, Y. Sasaki, J. Hagikura, Y. Hayashi, and T. Hirashima, "Learning effectiveness of computational thinking in a simple classification task while using a yes/ no chart learning system compared to using a visual programming learning system," Inf. Technol. Educ. Learn., vol. 1, Reg.p003, 2021.

[12] R. Okada, "Teachers' autonomy support in synchronous online learning environments," Inf. Technol. Educ. Learn., vol. 1, Reg.p004, 2021.

[13] G. Salmon, E-Moderating: The Key to Teaching and Learning Online. London, Kogan Page, 2000.

[14] T. Matsuda and N. Honna, "e-Mentoring guidelines: Implementation and evaluation," in Proc. E-Learn 2005-World Conf. on e-Learn. in Corporate, Government, Healthcare, and Higher Educ., G. Richards ed., pp. 920-925, 2005.

[15] M. Yagi, M. Suzuki, S. Tsuzuku, S. R. Murakami, and H. Nakano, "Effect of orientation courses on self-regulated learning strategies: Goal setting, planning, and execution," Inf. Technol. Educ. Learn., vol. 1, Pra.p002, 2021.

[16] R. Ikejiri, R. Yamamoto, S. Nakano, K. Yoneda, and Y. Yamauchi, "Designing project-based learning to promote the social construction of knowledge by overcoming dissonance using G suite," Inf. Technol. Educ. Learn., vol. 1, Pra.p001, 2021.

[17] T. Mochizuki and M. Tsubakimoto, "Designing a collaborative learning environment for critical reading with peer response activity," Inf. Technol. Educ. Learn., vol. 1, Pra.p003, 2021.

[18] H. Mitsuhara and M. Shishibori, "Interactive digital signage system enabling viewers to answer quizzes by body actions," Inf. Technol. Educ. Learn., vol. 1, Dev.p001, 2021.

[19] D. Akamatsu and A. Goto, "Cluster analysis of failure beliefs among Japanese junior high school students: Perspectives from "failure prevention" to "failure promotion”," Inf. Technol. Educ. Learn., vol. 1, Sh.p001, 2021.

[20] K. Kotani and T. Yoshimi, "Estimation of English proficiency based on read-aloud performance and linguistic difficulty of sentences," Inf. Technol. Educ. Learn., vol. 1, Sh.p002, 2021.

[21] H. Hao and M. Yamada, "Review of research on content and language integrated learning classes from the perspective of the first principles of instruction," Inf. Technol. Educ. Learn., vol. 1, Rvw.p001, 2021.

[22] M. D. Merrill, "First principles of instruction," Educ. Technol. Res. Dev., vol. 50, no. 3, pp. 43-59, 2002. 